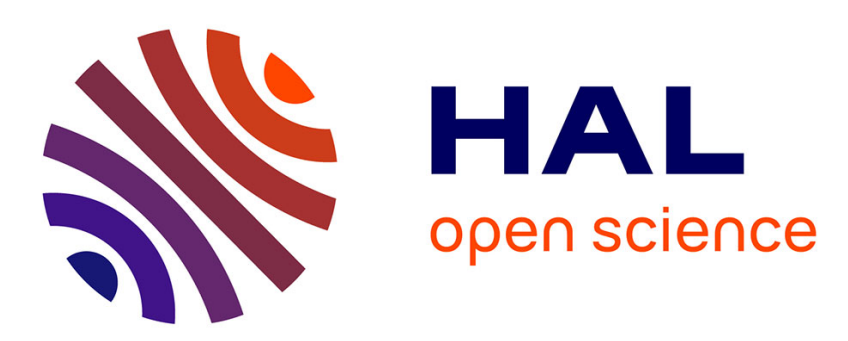

\title{
SLG fault detection in presence of strong capacitive currents in compensated networks
}

Wan-Ying Huang, Robert Kaczmarek

\section{To cite this version:}

Wan-Ying Huang, Robert Kaczmarek. SLG fault detection in presence of strong capacitive currents in compensated networks. IEEE Transactions on Power Delivery, 2007, 22, pp.2132-2135. hal-00242746

\section{HAL Id: hal-00242746 \\ https://hal-centralesupelec.archives-ouvertes.fr/hal-00242746}

Submitted on 6 Feb 2008

HAL is a multi-disciplinary open access archive for the deposit and dissemination of scientific research documents, whether they are published or not. The documents may come from teaching and research institutions in France or abroad, or from public or private research centers.
L'archive ouverte pluridisciplinaire HAL, est destinée au dépôt et à la diffusion de documents scientifiques de niveau recherche, publiés ou non, émanant des établissements d'enseignement et de recherche français ou étrangers, des laboratoires publics ou privés. 


\title{
SLG Fault Detection in Presence of Strong Capacitive Currents in Compensated Networks
}

\author{
Wan-Ying Huang and Robert Kaczmarek
}

\begin{abstract}
The detection of single line-to-ground (SLG) fault in compensated distribution networks can be hampered by important capacitive currents. The way of dealing this problem depends on particular regime where data is acquired. In transient regime the relays diagnosis based on analysis of charging components can deceive in massive presence of discharging currents. The latter however will disclose data for directional function, if sampling frequency is high enough for acquisition in wave propagation area.

The fault detection can also be out of reach of steady state methods which are based on detection of active component in faulty currents. Efficiency of these methods vanishes when strong capacitive currents squeeze the phase shift between faulty and sound zero sequence currents below actual acquisition limits. In such situation however it is still possible to get the faulty feeder indication from the way the residual currents cross the zero level soon after inception.
\end{abstract}

Index Terms-- Fault diagnosis, power distribution protection, compensated distribution system

\section{INTRODUCTION}

$\mathbf{I}_{\mathrm{n}}^{\mathrm{N}}$ case of low ohmic SLG faults in compensated distribution networks the directional function can be assured by transient relays which compare polarities of zero sequence charging components at main frequency, either of voltage versus currents on each feeder [1] or of their products on different feeders [2]. Some difficulties can arise however in presence of violent discharging transients. They grow with inception angle $\theta$, which determine pre-fault values of the faulty line voltage. The discharging currents are absent at $\theta=0^{\circ}$ but then they reach the charging currents' level when the inception angle is several degrees (Fig. 1), and grow rapidly. The most favorable conditions for generation of important transients are with low resistance fault when it occurs at inception angle $90^{\circ}$ in a capacitive network, be it a cabled system or a mixed one, composed of cables and lines.

In such conditions we can expect the extraction of main frequency component out of the charging currents to be more delicate an operation in cables than in lines. The charging

This work was supported in part by Tsing Hua University in Taiwan and by Schneider Electric, France

Wan-Ying Huang is with Supelec, Gif sur Yvette, France (phone:33 169 85 15 32; fax: 331698515 39; e-mail: wanying.huang@supelec.fr)

Robert Kaczmarek is with Supelec, Gif sur Yvette, France (e-mail: robert.kaczmarek@supelec.fr)
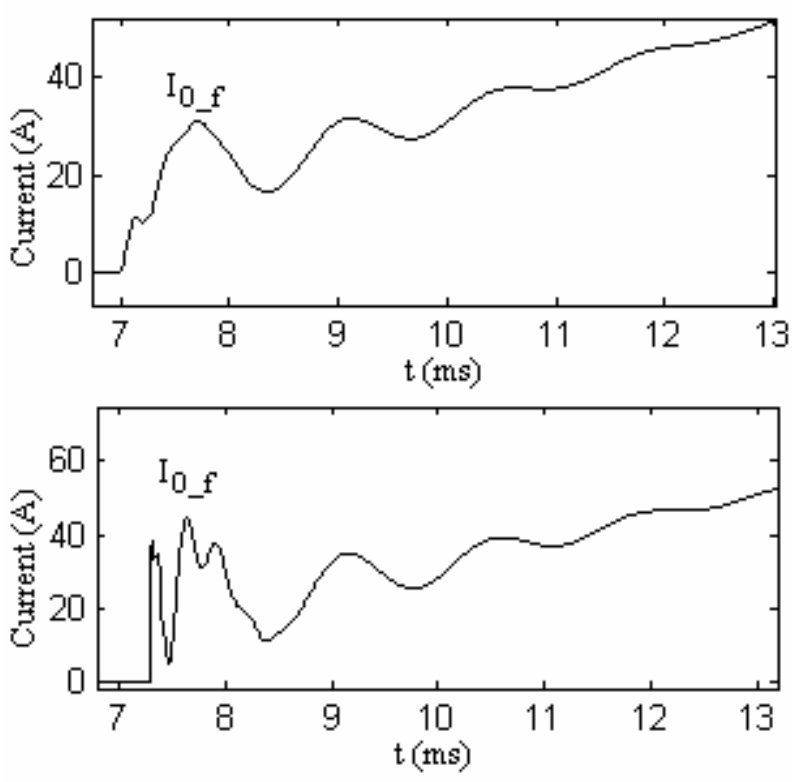

Fig. 1 Initial faulty feeder zero sequence currents in cables. The discharging currents of higher frequency are superimposed on the charging ones of lower frequency. Upper figure: $\theta=0^{\circ}$, no discharging components. Bottom: $\theta=5^{\circ}$, the discharging current's amplitude reach the level of charging components.

components in overhead lines [3] were reported to reach amplitudes 10-15 times the rated frequency amplitude whereas the discharging currents were estimated as several per cent of charging components. However, when replacing lines with cables, all the other conditions unchanged, the discharging currents will be more important than the charging ones, with frequency span between them diminishing.

A relevant example comparing amplitudes and frequencies of the main discharging and charging currents (Fig. 2) presents the amplitudes ratio $\mathrm{A}_{\mathrm{dis}} / \mathrm{A}_{\mathrm{ch}}$ rising from 0.25 (lines) to 1.5 (cables) and the frequency ratio $\mathrm{f}_{\mathrm{dis}} / \mathrm{f}_{\mathrm{ch}}$ diminishing from 11 to 6. The reason of these tendencies is with specific values of zero sequence capacitances in cables and lines.

Obviously, it is simpler a task to isolate a paramount and somewhat isolated component. The consequence for the transient relays, when applied in capacitive systems, can be an uncertain choice of window and trigger for acquisition and heavy standards on extraction of the relevant charging components. 

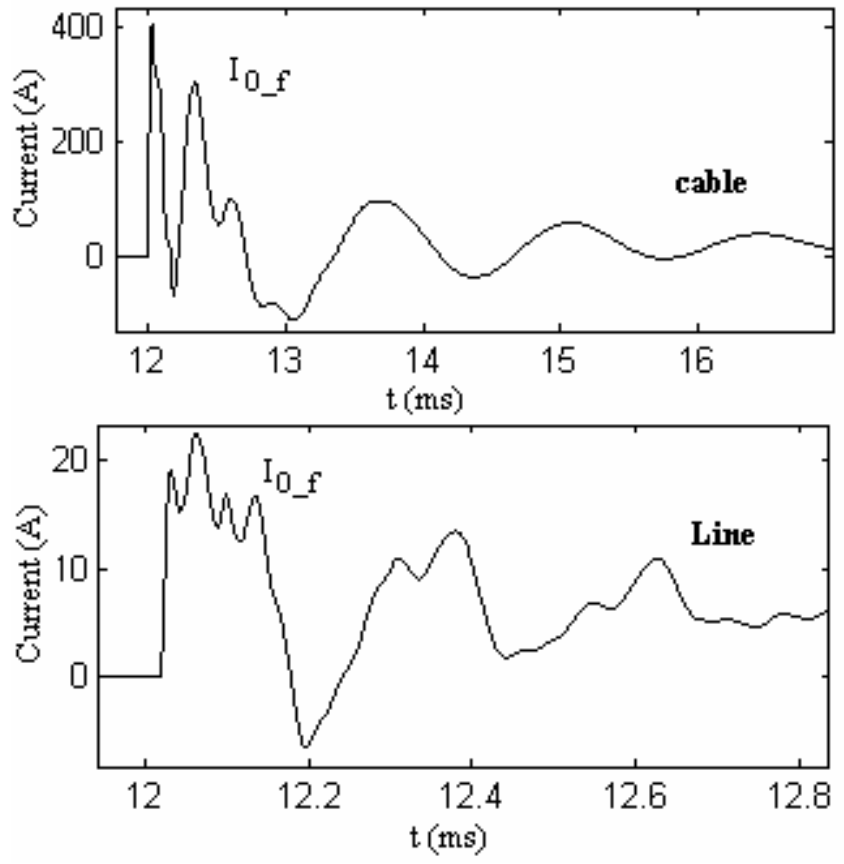

Fig. 2. The faulty feeder zero sequence currents in cables and lines of the same length and power transfer, with $1 \Omega$ fault resistance and $90^{\circ}$ inception angle. The discharging components in cables are of higher amplitudes than the charging components and the frequency ratio are different in cables and in lines.

The disturbing presence of the discharge components can however turn into an opportunity to make a correct directional decision. This opportunity is offered by rigorous waveform disposition in initial propagation zone, usually unexplored in distribution systems. However, as the high frequency acquisition procedures become simpler and cheaper, we are tempted with evaluation of possibilities of using the travelling wave regime to get directional function.

Strong capacitive currents are troublesome also in case of resistive faults, where relays discriminate faulty and sound feeders upon presence of active current component in residual currents. This can be achieved either by comparing signs of projections of zero sequence currents [4,5] or looking for phase advance [6,7] of the faulty zero sequence current over the sound ones. However, in steady state the strong capacitive currents diminish this phase advance, with possible inhibition of the discrimination capacities of relays.

Then the way to re-establish these capacities is to exploit data recorded in transient regime, where the apparent phase difference is more important than in the steady state.

The procedures which follow were modeled and simulated in EMTP using frequency dependant parameters.

\section{DIRECTIONAL FUNCTION OF DISCHARGING CURRENTS}

We consider a radial network (Fig. 3) with no discontinuities in feeders' impedances. The network is supplied through a transformer with secondary winding grounded through Petersen coil. An SLG fault is modeled as a resistance $R_{f}$.

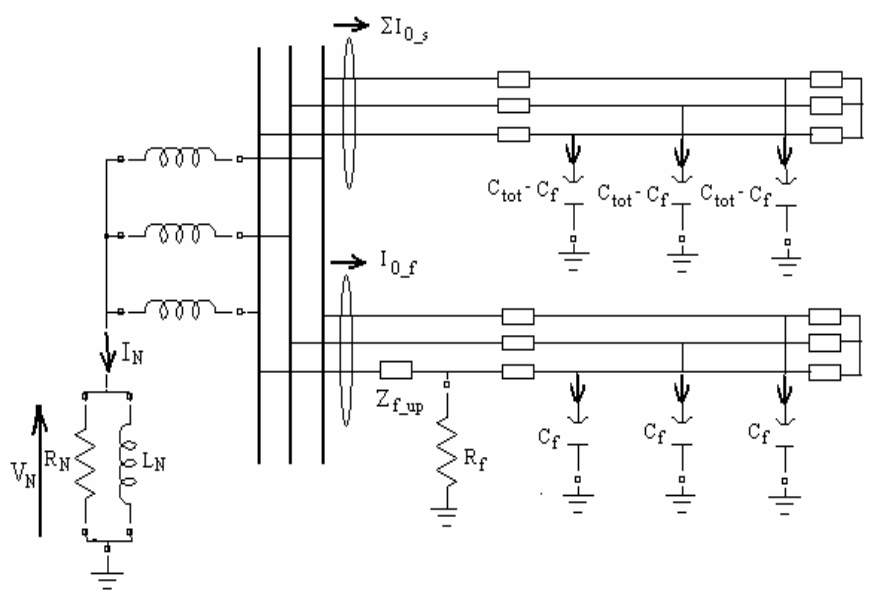

Fig. 3. A phase-to-ground fault in a radial network, all the sound feeders aggregated into one

At fault occurrence an initial voltage wave annulling the phase voltage travels along the faulty phase of the faulty feeder with negative amplitude, accompanied by current wave also of negative amplitude. Their shape will be modeled by multiple refractions and reflections from busbar, fault and loads. The faulty phase current arriving on busbar reflects and the resulting current is equally distributed among faulty phases of all the sound feeders. These faulty phase currents impose their waveform upon residuals in each feeder. Consequently, initial currents on the sound feeders will be measured with the same polarity and opposed to the polarity on the faulty feeder.

On each sound feeder the initial polarity regime will be over with first busbar reflection of wave getting back from loads. Its overall travel time is $2 l / v$, with $l$ - the feeder's length and $v$ - the wave velocity. This is the time interval where the current on the faulty phase of any sound feeder keeps its initial polarity unchanged. The shortest distance $l_{\mathrm{ss}}$ is with the shortest sound feeder and thus we get the duration of the initial polarity $\delta_{i p}=2 l_{s s} / v$, where $\mathrm{v}$ is the maximal modal velocity.

The parameter $f_{i p}=1 / \delta_{i p}$ determines the minimal sampling frequency necessary to get one point in the zone of a rigorous polarity disposition of residual currents.

For example, with the shortest length of a cable feeder being $2 \mathrm{~km}$ this frequency can be of $20-30 \mathrm{kHz}$. For practical reasons the frequency of about $100 \mathrm{kHz}$ is to be reckoned with.

In cables the propagation phenomena take place both in cores and sheaths. The fault we refer to is a core-to-sheath (and, eventually, -to-ground) piercing, with sheaths grounded on supply side or on both sides. In each of these cases the traveling waves are very similar and the initial polarity zone clearly exposed (Fig. 4). 


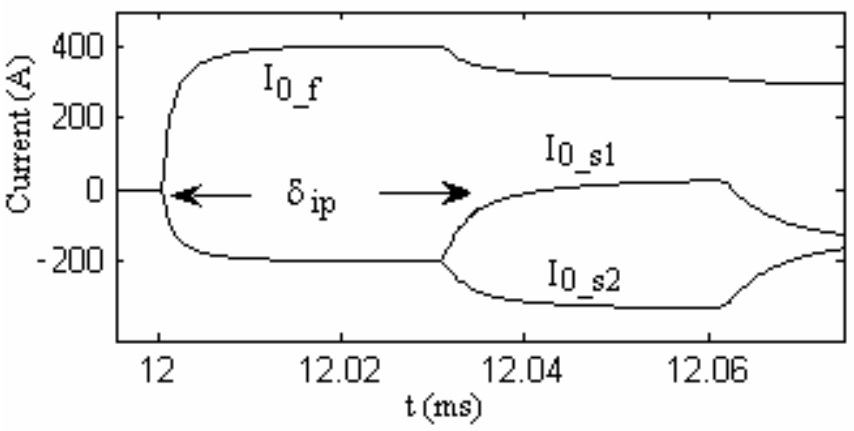

Fig. 4. The initial polarity zone in three feeders' network, zero sequence currents. The index s is for "sound" and f- for "faulty" feeder

The initial polarity time interval does not depend neither on fault position, nor fault resistance value. If scrutinized on all feeders it can point out from busbar to fault in systems with laterals [8]. In order to start tracing of the faulty feeder, the initial polarities of residual currents in all busbar connected feeders have to be compared. The beginning of the faulty chain is pointed with a unique sign, called "witness sign", being different from polarity of all the other feeders. Then we follow current sensors on feeders with the same "witness" polarity. The fault is at the end of the chain.

This will be illustrated in the case of an SLG fault on the feeder $d$ in a five feeders network (Fig. 5).

The rising current profiles have been recorded first on feeders $d$ and e (Fig. 6). When the traveling waves arrive to busbar, the sign of the current measured on the feeder $\mathbf{c}$ is different than those measured on the feeders $\mathbf{a}$ et $\mathbf{b}$. The feeder c disclosing the "witness sign", it points out to the feeder $\mathbf{d}$ as the fault location.

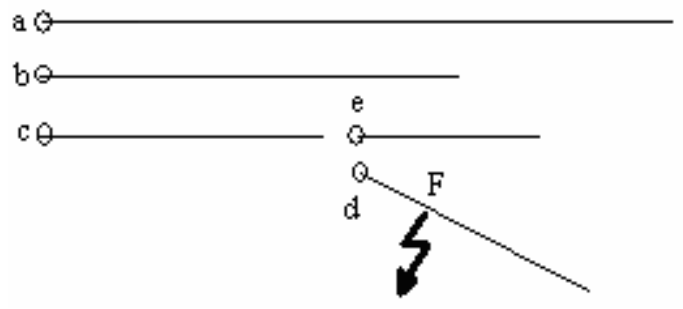

Fig. 5. A phase-to-ground fault F on the feeder "d" in a network with laterals

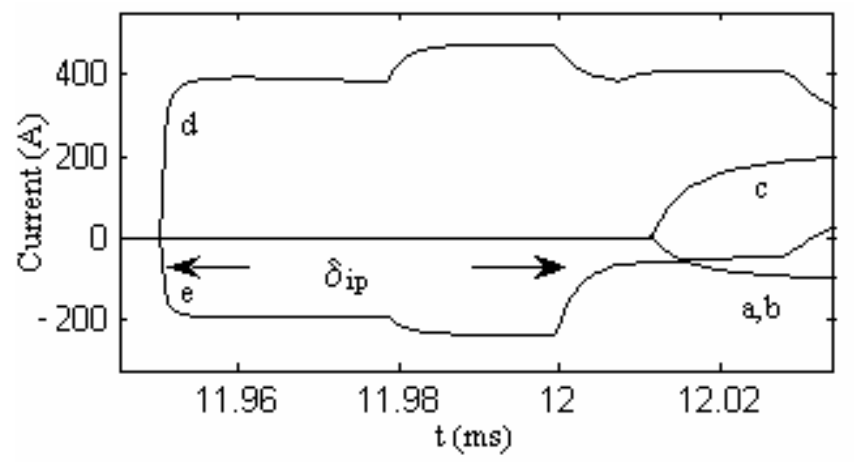

Fig. 6. Residual currents within initial polarity zone in the network of Fig.5
All methods based on analysis of traveling waves are highly sensitive to impedance mismatches, what results in severe conditions on their application in distribution networks. Feeders with single tee joints can be analyzed relatively easily, unless the initial polarity zone is too short to be detected. On the contrary, multiple tee joints and joints between cables and lines in mixed systems make the detection problem inextricable in terms of traveling waves' analysis.

\section{THE PHASE DIFFERENCE OF THE ZERO SEQUENCE CURRENTS}

\section{A. Principle}

The steady state SLG fault regime can be analyzed on equivalent residual circuit (Fig. 7), where V" is the voltage over a SLG fault emplacement in absence of the fault, $I_{0_{-} \mathrm{f}}$ zero sequence current on the faulty feeder, $\Sigma I_{0_{-} s}$ - the sum of zero sequence currents on all the sound feeders and $\mathrm{I}_{\mathrm{N}}$ is the neutral point current composed of a resistive and an inductive components.

During permanent fault regime, an active current component is present in zero sequence current $I_{0_{f} f}$ on the faulty feeder. The resulting phase difference between the faulty and the sound zero sequence currents $I_{O_{-} s}$ (Fig. 8) is the basis of traditional wattmetric method of detection.

In low capacitive lines the phase advance can be almost $90^{\circ}$, because under the effect of compensation we have (Fig. 7):

$$
I_{0_{-} f}=-I_{N}-\sum I_{0_{-} s}=-I_{c_{-} f}-I_{R N}
$$

where the faulty residual $I_{0 f}$ is dominated by its active component $I_{R N}$.

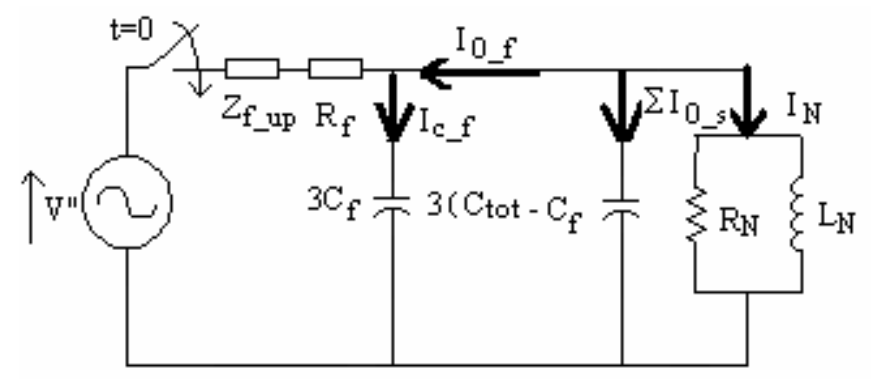

Fig. 7. An equivalent residual circuit of the faulty network on Fig. 3

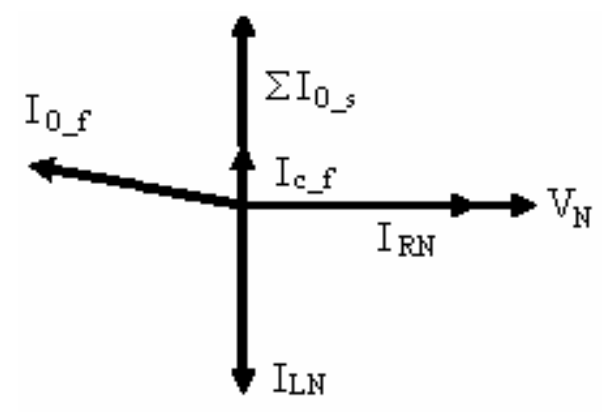

Fig.8. The faulty feeder diagnosis is obvious if there is sufficient phase advance of $\mathrm{I}_{0_{-} \mathrm{f}}$ over $\mathrm{I}_{0_{-}}$. 
It is then easy to take direction decision. In cables however the faulty feeder capacitive current $I_{c-f}$ dominates the composition of $I_{0 f}$ and diminishes readability of the phase advance, particularly with fault on a long feeder or in case of system over tuning.

We have simulated a three feeders' cable system of capacitive currents $15 \mathrm{~A}+10 \mathrm{~A}+5 \mathrm{~A}$, the fault installed on the $15 \mathrm{~A}$ feeder, with $100 \%$ tuning and the fault resistance values ranging from $1 \Omega$ to $1000 \Omega$. In all cases the actual phase advance in steady state was less than one sample step at $600 \mathrm{~Hz}$ sampling frequency, this frequency being used in certain relays.

Fortunately, when the phase advance in steady state becomes undetectable, we can look upon an analogous parameter in transient regime, where it can be much larger.

This is a consequence of the way the transient regime develops, beginning just after the fault inception with phase opposition between faulty and sound current residuals and finishing in steady state with a slight phase advance of the faulty residual over all the sound ones. This development is correlated with evolution of the neutral point current $I_{N}$ smoothly growing from zero to its permanent value. During the first millisecond after fault inception it can grow very slowly, particularly with resistive faults, because of high values of the neutral point elements $L_{N}$ and $R_{N}$.

On the contrary, the feeders' line-to-ground capacitors $C_{f}$ and $C_{s}$ charge and discharge vigorously. During a short time interval the neutral point current $I_{N}$ is negligible comparing to capacitive zero sequence currents.

The latter being under the same charging conditions, the faulty zero sequence current is initially in phase opposition to the sound feeders zero sequence currents, see (2):

$$
I_{0_{-} f}=-\left(\sum I_{0_{-} s}\right)
$$

and proceeds toward zero level (Fig. 9) with different polarities.

The identification of faulty feeder operates then with aid of following algorithm.

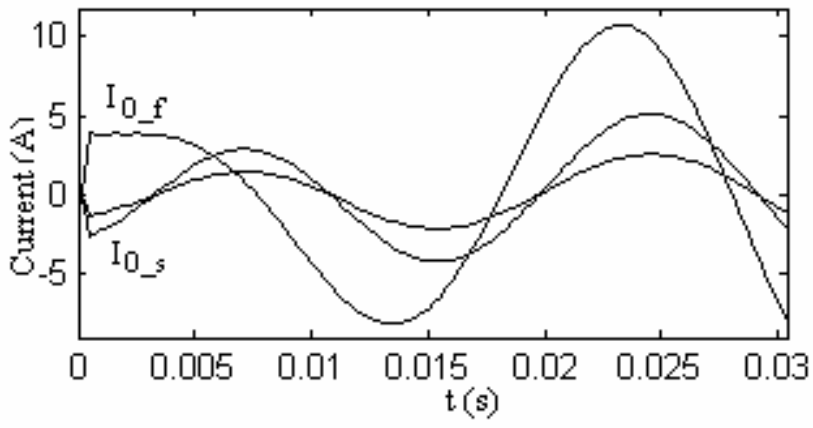

Fig. 9 Faulty and sound current residuals in case of resistive fault, non filtered curves $\left(\mathrm{R}_{\mathrm{f}}=1 \mathrm{k} \Omega, \theta=90^{\circ}\right)$

\section{B. Algorithm}

We detect the slopes of filtered residuals at their first zero crossing after the fault inception. If all but one witness the same slope sign, then we can declare the latter as the faulty one without even controlling its zero crossing:

$$
\begin{aligned}
& \text { IF } I_{k}\left(t_{0}\right)=0 \text { for } k=1 \cdots n-1 \\
& \text { AND } \operatorname{sgn}\left(\frac{d I_{1}}{d t}\right)=\operatorname{sgn}\left(\frac{d I_{2}}{d t}\right)=\cdots \operatorname{sgn}\left(\frac{d I_{n-1}}{d t}\right) \text { at } t=t_{0} \\
& \text { THEN the } n^{\text {th }} \text { feeder is the faulty one }
\end{aligned}
$$

This is a one shoot procedure, without possibility of verification. On the other hand it is a conclusive test, as the matter goes about unambiguous identification of slopes' signs.

\section{CONCLUSION}

We think that strong capacitive currents, sometimes generating unfavorable conditions for protection relays in compensated systems, can be exploited as carriers of relevant information.

Whenever extremely rapid information is required, we can find it when treating the discharging currents as useful, at a price of higher sampling frequency. After fault inception we dispose of several tens of microseconds to get the data in wave propagation area. This can make sense in simple distribution systems, with single ramification per feeder and homogenous line impedance.

We can also make useful the presence of strong capacitive currents in permanent fault regime, where these currents occult detection of faulty feeder. In such cases the diagnosis based on phase advance of the faulty residual current over the sound residuals is better assured when tracing the corresponding apparent phase advance in transient regime.

Both propositions need the current data be centralized, they work on one or only few data points in a very short time span. These drawbacks are price for matching consequences of cable proliferation in resonant grounded distribution networks.

\section{ACKNOWLEDGMENT}

The authors are grateful to Mr Volker Leitloff for his expert comments on initial draft of this paper.

\section{REFERENCES}

[1] A. Nikander, E.Lakervi, and J.Suontausta, "Applications of transient phenomena during earth faults in electricity distribution networks", Proc. Conf. Energy Management and Power Delivery, pp. 234-239, 1995

[2] J. Coemans and J._C. Maun, "Using the EMTP and the Omicron to design a transients based digital ground-fault relay for isolated or compensated networks", Int. Conf. Power System Transients IPST, 1995

[3] M. Lehtonen, "Fault management in electrical distribution systems", Final Report of the CIRED working group WG03, Espoo, Finland, December 1998

[4] D. Griffel, Y. Harmand, V. Leitloff and J. Bergeal, "Anew deal for safety and quality on MV networks", IEEE Trans. Power Delivery, vol. 12, nº, pp. 1428-1433, Oct. 1997

[5] T. Welfonder, V. Leitloff, R. Feuillet and S. Vitet, "Location strategies ans evaluation of detection algorithms for earth faults in compensated 
MV distribution systems", IEEE Trans. Power Delivery, vol. $15, \mathrm{n}^{\circ} 4$, pp. 1121-1128, Oct. 2000

[6] P. Bastard, P. Bertrand, T. Emura, M. Meunier, "The Technique of Finite-Impulse-Response Filtering Applied to Digital Protection and Control of Medium Voltage Power System", IEEE Trans. Power Delivery, vol 7, n², pp. 620-626, April 1992

[7] T. Segui, P. Bertrand, M. Guillot, P. Hanchin and P. Bastard, "Fundamental Basis for Distance Relaying with Parametrical Estimation", IEEE Trans. Power Delivery, vol. 16, n 1, pp. 99-104, Jan. 2001

[8] R.Kaczmarek and W-Y.Huang, "Directional Function in Distribution Networks through Wave Propagation", Int. Conf. PowerTech, St Petersburg 2005

\section{BIOGRAPHIES}

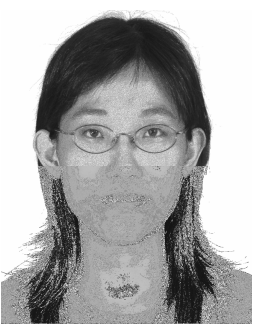

Wan-Ying HUANG has graduated from Tsing Hua University in Taiwan with Master Degree in 2002 and in 2006 has got her PHD in Ecole Supérieur d'Electricité SUPELEC and University Paris XI in France. She is now on a post doctoral research program in SUPELEC, working on protections and voltage stability in electrical systems and optimal design of electric machines.

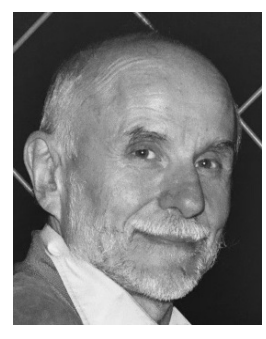

Robert KACZMAREK is professor in Ecole Supérieure d'Electricité (Supelec) in France. His research interest is with power networks (fault detection, network protection, and parameters identification), magnetism (domain observation, loss prediction and measurements in soft and hard magnetic materials) and design of electric machines. 